\title{
ANALISIS HUBUNGAN ANTARA KINERJA DENGAN STRESS KERJA DAN KEPUASAN KERJA KARYAWAN CUSTOMER SERVICE TELKOMSEL GERAI GRAPARI MAL PONDOK INDAH 3 DI JAKARTA SELATAN
}

\author{
Mery Christina Purnama \\ STIE Unisadhuguna Jakarta, Indonesia \\ Email : mery.christina@ubs-usg.ac.id
}

\begin{abstract}
Abstrak
Pendahuluan : Manusia adalah salah satu faktor penting dalam sebuah perusahaan. Proses untuk meningkatkan kepuasan dan kinerja karyawan, perusahaan perlu memperhatikan penanganan stres kerja. Penelitian ini menganalisis faktor stres pekerjaan dan kepuasan kerja pada karyawan layanan pelanggan Grapari Telkomsel di Mall Pondok Indah 3, Jakarta Selatan. Penelitian wawancara ini dilakukan terhadap 1 HRD (Human Resource Department), 1 SPV (supervisor), 1 TL (team leader), dan 5 karyawan customer service.
\end{abstract}

Tujuan : Penelitian wawancara ini menunjukkan bahwa perusahaan perlu memberikan kesempatan yang lebih luas untuk berkarier di perusahaan, dan juga diberikan insentif/bonus/imbalan yang dapat memberikan motivasi untuk mencapai kepuasan kerja dan mengurangi stres kerja. Penelitian ini menunjukkan bahwa indikator dominan yang menyebabkan stres kerja hanya memiliki 4 faktor: Penanganan keluhan keras, target, pengadaan shift, dan pergeseran distribusi. Wawancara ini juga menunjukkan bahwa layanan pelanggan memiliki kepuasan kerja yang baik.

Metode : Jenis penelitian yang digunakan kualitatif dengan pendekatan deskriptif yaitu data penelitian berupa kata-kata, wawancara, catatan lapangan, dan dokumen. Teknik penelitian yang dilakukan yaitu penelitian lapangan.

Hasil : Kepuasan kerja dengan kinerja karyawan memiliki pengaruh yang positif. Hubungan tersebut mengartikan bahwa semakin puas karyawan kepada perusahaan, maka performa kerja dan hasil kerja yang ditunjukkan akan semakin baik atau sebaliknya.

Kesimpulan : Pemberian gaji yang sesuai dengan pekerjaan adalah salah satu indikator kepuasan dalam bekerja.

Kata Kunci : Stres Pekerjaan, Kepuasan Kerja, dan Kinerja Karyawan.

\section{Abstract}

Introduction : Humans are one of the important factors in a company. The process to improve employee satisfaction and performance, companies need to pay attention to handling work stress. This study analyzed the factors of job stress and job satisfaction in Grapari Telkomsel customer service employees at Pondok Indah Mall 3, South Jakarta. This interview was conducted on 1 HRD (Human Resource Department), 1 SPV (supervisor), 1 TL (team leader), and 5 customer service employees.

Objective : Research shows that companies need to provide a wider range of opportunities for a career in the company, and are also given incentives / bonuses / rewards that can provide motivation to achieve job satisfaction and reduce work 
stress. The study showed that the dominant indicators that cause work stress have only 4 factors: Handling harsh complaints, targets, shift procurement, and distribution shifts. This interview also shows that customer service has good job satisfaction.

Method : The type of research used qualitatively with a descriptive approach is research data in the form of words, interviews, field records, and documents. The research techniques carried out are field research.

Results : Job satisfaction with employee performance has a positive influence. The relationship means that the more satisfied employees are to the company, the better the work performance and work results shown will be better or vice versa.

Conclusion : The provision of salaries that are in accordance with the work is one of the indicators of satisfaction in work.

Keywords : Job Stress, Job Satisfaction, and Employee Performance.

\section{Pendahuluan}

Seperti saat ini dalam menghadapi arus globalisasi, sumber daya manusia (SDM) memegang peranan yang sangat penting dalam suatu perusahaan (Samsuni, 2017). Berhasil atau tidaknya suatu perusahaan dalam mencapai tujuan yang telah ditetapkan sebelumnya sangat tergantung pada kemampuan sumber daya manusia (karyawan) dalam menjalankan tugas-tugas yang diberikan (Erlangga, 2017). Apabila individuindividu dalam perusahaan yaitu SDM-nya sebagai karyawan dapat bekerja secara efektif dan efisien maka perusahaan tersebut juga akan berjalan secara efektif dan efisien dalam menuju pada tujuan perusahaan. Dengan kata lain kelangsungan dan performa suatu perusahaan itu ditentukan oleh kinerja karyawannya (Andi Prayogi \& M Nursidin, 2018). Setiap perusahaan selalu mengharapkan karyawannya mempunyai prestasi dalam pengertian bekerja secara produktif, karena dengan memiliki karyawan yang produktif akan memberikan sumbangan yang optimal bagi peraihan tujuan perusahaan.

Perusahaan ini merupakan BUMN yang bergerak dibidang jasa layanan telekomunikasi dan jaringan wilayah Indonesia yang menyediakan beragam layanan komunikasi termasuk layanan internet koneksi jaringan telephone, multimedia dan pembangunan infrastruktur menyeluruh yang dikenal dengan Indonesia Digital Network (IDN).

Kinerja atau performance merupakan gambaran mengenai tingkat pencapaian pelaksanaan suatu program kegiatan atau kebijakan dalam mewujudkan sasaran, tujuan, visi dan misi organisasi yang dituangkan melalui perencanaan stretegis suatu organisasi (Lengkong, Lengkong, \& Taroreh, 2019).

Menurut (Hastono, 2013) berpendapat bahwa kepuasan kerja berhubungan erat dengan sikap karyawan terhadap pekerjaannya sendiri, situasi kerja, kerjasama antara pimpinan dengan sesama karyawan.

Menurut (Asih, Widhiastuti, \& Dewi, 2018) stres dapat berarti banyak, dari perpektif orang biasa, stres dapat digambarkan sebagai perasaan tegang, gelisah, atau 
khawatir. Secara ilmiah, semua perasaan ini merupakan menifestasi dari pengalaman stres, suatu respon terprogram yang kompleks untuk mempersepsikan ancaman yang dapat menimbulkan hasil yang positif maupun negatif.

Dari beberapa teori yang mengemukakan bahwa job performance seorang karyawan berkaitan erat dengan faktor-faktor lain juga di luar faktor kepuasan karyawan dan stres kerja sebagaimana dijelaskan di atas, menurut (Simanjuntak, Nadapdap, \& Winarto, 2017) tingkat pendidikan dan keterampilan kerja, kompetensi, tanggung jawab, latar belakang, etos kerja, dukungan organisasi, psikologis.

Berdasarkan uraian pada latar belakang, maka masalah yang akan di bahas pada penulisan ini, yaitu: bagaimana hubungan antara Kinerja dengan Stres Kerja Karyawan customer service, Kinerja dengan Kepuasan Kerja Karyawan customer service, Manakah diantara Stres Kerja dan Kepuasan Kerja yang lebih memiliki hubungan dominan dengan Kinerja Karyawan customer service dan Manakah diantara Kepuasan Kerja dan Stres Kerja yang lebih memiliki hubungan dominan dengan Kinerja Karyawan customer service di Grapari Telkomsel Mall Pondok Indah 3?

Berdasarkan rumusan masalah tersebut, maka tujuan dalam penelitian ini untuk mengetahui apakah ada hubungan antara Kinerja dengan Stres Kerja Karyawan customer service, Kinerja dengan Kepuasan Kerja Karyawan customer service dan Untuk mengetahui mana yang lebih memiliki hubungan dominan Stres Kerja dan Kepuasan kerja dengan kinerja kinerja customer service dan mana yang lebih memiliki hubungan dominan Kepuasan Kerja dan Stres Kerja dengan kinerja karyawan customer service di Grapari Telkomsel Mall Pondok Indah 3?

\section{Metode Penelitian}

Jenis penelitian yang digunakan kualitatif dengan pendekatan deskriptif yaitu data penelitian berupa kata-kata, wawancara, catatan lapangan, dan dokumen. Setelah data itu dikumpulkan, diolah dan dijelaskan sesuai apa adanya (Sugiyono, 2017).

Teknik penelitian yang dilakukan yaitu penelitian lapangan (field research) (Elitear \& Koto, 2016) dimana penulis langsung terjun pada objek penelitian yaitu Gerai GraPARI Telkomsel Mal Pondok Indah 3 Jakarta Selatan yang bergerak di bidang Telekomunikasi khususnya Telepon Bergerak Seluler dengan sistm GSM (Global System for Mobile Communication). Yang memiliki berbagai merk produk yang dipasarkan di Indonesia menjadi produk paska bayar dan prabayar.

Sesuai objek penelitian ini, yaitu customer service di Gerai Grapari Telkomsel Mal Pondok Indah 3 Jakarta Selatan, maka peneliti menetapkan populasi yang menjadi objek dari penelitian ini adalah customer service di Gerai Grapari Telkomsel Mal Pondok Indah 3 Jakarta Selatan. Dalam penelitian ini penelitian akan menggunakan Purposive Sampling. Menurut (Nurdiani, 2014) Purposive Sampling adalah teknik pengambilan sampel sumber data dengan pertimbangan tertentu, misalnya orang tersebut dianggap paling tahu tentang apa yang kita harapkan.

Sampel yang akan dijadikan penelitian ini adalah berjumlah HRD, SPV, Team Leader, dan 5 customer service. Teknik pengumpulan data yang dilakukan yaitu 
penelitian lapangan (field research) dimana penulis langsung terjun pada objk penelitian yaitu Gerai GraPARI Telkomsel Mal Pondok Indah 3 Jakarta Selatan yang merupakan perusahaan yang bergerak dibidang Telekomunikasi.

Peneliti akan melakukan wawancara dengan bagian HRD, SPV, Team Leader, dan 5 customer service. Dalam penelitian ini data primer dan sekunder yang diambil berasal dari dokumen-dokumen yang berkenaan dengan prosedur pelaksanaan (Nilamsari, 2014).

\section{Hasil dan Pembahasan}

\section{Untuk mengetahui apakah ada hubungan antara Kinerja dengan Stres Kerja Karyawan customer service di Grapari Telkomsel Mall Pondok Indah 3?}

Menurut karyawan customer service yang bernama Alifabi untuk kondisi stres kerja karyawan customer service di GraPARI Tekomsel Mall Pondok Indah 3 Jakarta Selatan, Tingkat stres kerja karyawan customer service di GraPARI Mall Pondok Indah 3 Jakarta Selatan salah satu customer service pernah mengalami complain dari customer dikarenakan pulsa ketarik lalu bilang pulsanya habis padahal tidak dipakai, customer service langsung mengecek dari sistem ternyata customer pakai internet tapi paket internetnya tidak ada dan untuk data selulernya dihidupkan otomatis untuk pulsanya ketarik jadi pulsanya bisa habis.

Faktor stres kerja yang paling banyak dirasakan adalah beban kerja yang berat, sebagai contohnya adalah beban kerja seperti hard complain adalah hal yang tidak mudah, dalam kondisi yang banyak tekanan dari pelanggan, sebagai professional harus tetap memberikan solusi yang baik dengan menjelaskan dengan ramah dan murah senyum.

Dilain sisi, dalam berkesempatan berkarier, juga menjadi faktor yang mempengaruhi stres kerja. Jenjang karier tertinggi di dalam GraPARI Telkomsel adalah Supervisor (Kepala Cabang Grapari), untuk dapat dijenjang ini diperlukan pengalaman dan dedikasi lebih dari 5 tahun dialami perusahaan baru dapat mengikuti kualifikasi supervisor. Diikuti Team Leader yang harus berpengalaman menjadi seorang customer service minimal 1 tahun, dan harus mengikuti proses seleksi yang cukup ketat agar berada diposisi Team Leader karna harus memiliki kredibilitas seperti penjualan yang stabil, complain handling yang baik dan tingkat disiplin yang tinggi. Beberapa customer service perlu waktu lama agar dapat berada diposisi tertinggi dari kariernya dikarenakan ketatnya persaingan antar customer service.

Berdasarkan hasil penelitian didapat hasil stres kerja berpengaruh negatif terhadap kinerja karyawan. Jika stres kerja meningkat maka akan mengurangi potensi kinerja karyawan dan jika sebaliknya stres kerja menurun maka akan meningkatkan potensi kinerja karyawan penelitian ini sejalan dengan yang dilakukan oleh (Riani \& Putra, 2017), oleh karena itu jika terjadi pengurangan fasilitas dan pengurangan beberapa tunjangan kesejahteraan karyawan dan keberhasilan karyawan lain menjadi pesaing kinerja. 


\section{Untuk mengetahui apakah ada hubungan antara Kinerja dengan Kepuasan} Kerja Karyawan customer service di Grapari Telkomsel Mall Pondok Indah 3?

Menurut karyawan customer service yang bernama Moh Firmansyah untuk kondisi kepuasan kerja karyawan customer service di GraPARI Tekomsel Mall Pondok Indah 3 Jakarta Selatan, rasa kekeluargaan yang baik terbukti membuat suasana kerja yang nyaman, selain harmonis hubungan interpersonal dengan rekan kerja, ada kondisi ruangan kerja yang nyaman.

Selain dari insentif, salah satu faktor kepuasan kerja juga disadari dengan penghargaan yang diterima atas kinerja pegawai customer service yang sudah diberikan. Penghargaan yang dimaksud bisa berupa verbal dan nonverbal, sebagai contohnya untuk penghargaan yang nonverbal berupa sertifikat atau piagam "The Best Customer Service of the Month", serta untuk yang verbal seperti ucapan selamat atas pencapaian target yang sudah dilakukan saat briefing awal bulan, agar karyawan customer service yang lain dapat memotivasikan untuk dapat lebih produkif dan juga diharapkan dapat meningkatkan kepuasan kerja para karyawan customer service.

Salah satu faktor kepuasan kerja adalah kesempatan untuk promosi atau jabatan yang adil pada setiap customer service (Qoidah, 2021). Bukan hal yang mudah untuk seorang customer service untuk dapat karier yang gemilang dalam waktu yang singkat. Pengalaman, kinerja loyalitas dan pencapaian target adalah salah satu indikator pegawai dapat mengembangkan karier serta mendapatkan promosi dari supervisor, referensi dari Team Leader juga menentukan kebijakan promosi ke jenjang karier selanjutnya.

Pekerjaan yang menyenangkan adalah pekerjaan yang dilakukan dengan rasa senang, sehingga tidak menjadi beban kerja yang membuat karyawan tidak nyaman dengan pekerjaan yang dijalankan. Pekerjaan yang menyenangkan juga dapat menjadi faktor kepuasan kerja yang dapat membuat tingkat produktivitas semakin tinggi (Lucia, Kawet, \& Trang, 2015).

Pada penelitian ini mengungkapkan bahwa kepuasan kerja mempunyai pengaruh yang positif terhadap kinerja karyawan. Kepuasan kerja dengan kinerja karyawan memiliki pengaruh yang positif. Hubungan tersebut mengartikan bahwa semakin puas karyawan kepada perusahaan, maka performa kerja dan hasil kerja yang ditunjukkan akan semakin baik atau sebaliknya. Jika seseorang merasakan kepuasan dalam pekerjaannya maka semangat kerjanya akan semakin meningkat. Dorongan tersebut dapat memudahkan untuk mencapai tujuan yang telah ditetapkan oleh perusahaan. Dengan demikian dapat disimpulkan bahwa tinggi rendahnya kepuasan kerja karyawan akan berpengaruh terhadap kinerja. Apabila kepuasan kerja tercapai maka kinerja karyawan akan tinggi, begitu pula sebaliknya. Gaji sesuai dengan jabatan kerja, pimpinan yang memperlakukan karyawan dengan baik, rekan kerja dalam bergaul tidak membedakan, perusahaan memberi fasilitas yang mendukung pekerjaan dan pekerjaan sesuai dengan harapan 


\section{Untuk mengetahui mana yang lebih memiliki hubungan dominan Stres Kerja dan Kepuasan kerja dengan kinerja kinerja customer service di Grapari Telkomsel Mall Pondok Indah 3?}

Mengenai stres kerja yang terjadi, bahwa ada 3 faktor indikator dominan yang dapat memicu stres kerja. Senjata utama seorang customer service adalah informasi tentang segala hal yang berkaitan dengan perusahaan, baik profil, produk dan segala yang berkaitan dengan sistem yang diterapkan dalam perusahaan. Jadi, customer service harus menguasai semua hal yang berbau informasi tentang perusahaan dan menjadi kewajiban perusahaan untuk memberikan informasi kepada customer servicenya, kecuali yang berkaitan dengan keuangan. Suatu pelyanan akan terbentuk karena adanya proses pemberian layanan tertentu dari pihak penyedia layanan kepada pihak yang dilayani.

Faktor yang pertama, adalah menangani pelanggan hard complain, menurutnya hal ini menjadi sulit karna seorang customer service diharapkan dapat memberikan solusi yang baik dan tenang pada saat memberikan penjelasan dengan tidak terpancing emosi.

Setiap kegiatan diarahkan untuk mencapai satu titik tujuan. Tujuan inilah yang selanjutnya menjadi motivasi banyak orang dalam melaksanakan kegiatan. Sebagai seorang pekerja, salah satu hal yang ingin dicapai dalam kehidupan atau kegiatan kerja adalah mencapai hasil maksimal yang mampu mambawa orang tersebut sampai pada puncak kemampuan. Dengan orientasi seperti ini, setidaknya ada sesuatu yang mendorong orang itu untuk segera mencapainya. Orang pasti akan selalu berusaha untuk mencapai hasil terbaik dari sebuah pekerjaan.

Faktor kedua adalah tidak tercapainya target penjualan setiap bulan meningkat yang diberikan pada tiap masing-masing customer service. Customer service mengandalkan visit untuk mencapai target KPI (Key Performance Indicator) 1 customer service menghandle 20, banyak hal yang menyebabkan tidak tercapainya target bulanan diantaranya yang paling sering terjadi adalah sistem aplikasi yang offline yang membuat penjualan tidak bisa dilakukan.

Pengadaan shift kerja menimbulkan banyak masalah terutama kurang dapat menyesuaikan diri dengan jam kerja yang dijalankan. Apabila perusahaan menggunakan pembagian waktu shift kerja lambat maka pencapaian kualitas dan kuantitas pekerjaan yang dicapai customer service semakin baik. Lambatnya sistem rotasi yang digunakan membuat customer service dapat mengatur pola hidupnya dengan cukup baik. Apabila pergantian customer service terhadap sistem shift kerjanya tinggi, maka semakin menurun kemampuan diri customer service untuk mencapai tujuannya. Seringnya customer service yang meminta berganti shift semakin memperburuk pola hidup para customer service. Penelitian yang telah dilakukan oleh (Nuryanti, 2016) bahwa shift kerja mempengaruhi kondisi fisik, psikologis, dan gangguan tidur yang memperburuk. 
Faktor yang terakhir adalah pembagian shifting jika ada salah satu karyawan customer service yang tidak masuk maka untuk karyawan yang stand by akan long shift untuk back up yang tidak masuk.

\section{Untuk mengetahui mana yang lebih memiliki hubungan dominan Kepuasan Kerja dan Stres Kerja dengan kinerja karyawan customer service di Grapari Telkomsel Mall Pondok Indah 3?}

Kepuasan kerja karyawan suatu perusahaan tidak terlepas dari faktor gaji yng diterima karena dengan meningkatnya tingkat pendapatan karyawan, akan dapat meningkatkan semangat kerja yang pada akhirnya karyawan akan merasa puas dengan apa yang diperolehnya. Realitanya, tidak semua perusahaan memberikan imbalan yang layak kepada karyawan, sehingga menimbulkan permasalahan seperti karyawan merasa tidak puas dalam bekerja. Pemberian gaji dari perusahaan kepada karyawan bertujuan agar karyawan puas dengan jerih payahnya sehingga karyawan diharapkan bekerja dengan baik. Sebab tenaga kerja manusia mempunyai perasaan sehngga tidak dapat diperas sedemikian rupa demi kepentingan perusahaan saja. Menurut Hulin (1966) gaji merupakan faktor utama untuk mencapai kepuasan kerja.

Pemberian gaji yang sesuai dengan pekerjaan adalah salah satu indikator kepuasan dalam bekerja. Untuk sistem di Grapari Telkomsel Mall Pondok Indah 3 Jakarta Selatan penggajian didasarkan atas dasar absensi dan performa, dimana selain gaji pokok juga dilihat dari aspek penilaian yang lain juga. Dalam hal ini banyak memang upah yang didapatkan tidak sama rata dengan karyawan customer service yang lain, dikarenakan penilaian atau performa yang dinilai masih kurang.

Semakin sering kontak dengan rekan kerja dan semakin banyak waktu diluangkan bersama, keeratan tim semakin tinggi. Dengan semakin berinteraksi, sesama rekan kerja akan saling mengenal satu sama lain dan menjadi lebih setia pada tim.

Hasil dari keeratan tim dibagi menjadi dua kategori yaitu moral dan produktivitas. Moril menjadi lebih tinggi dalam tim yang erat karena meningkatnya komunikasi diantara rekan kerja, iklim tim yang bersahabat, mempertahankan keanggotaan karena komitmen pada rekan kerja, loyalitas, dan partisipasi anggota dalam keputusan dan aktivitas tim.

Dalam kehidupan kerja modern saat ini, semakin disadari bahwa terdapat hubungan yang erat antara rekan kerja dan antara satu tugas dengan tugas lainnya (Nugraha \& Suherna, 2019). Ini berarti, sangat sulit bila tugas dikerjakan hanya oleh seorang karyawan saja, terutma bila tugas tersebut bersifat pemecahan masalah. Konsekuensinya adalah keharusan bekerja satu tim. Berdasaran kenyataan bahwa suatu masalah terpecahkan dengan lebih baik apabila pemecahannya dipikirkan oleh suatu kelompok disbanding dengan apabila dikerjakan sendiri oleh seseorang.

Memiliki rekan kerja yang bersahabat, rasa kekeluargaan yang dibangun dan rasa memiliki satu sama lain membuat hubungan interpersonal sesama rekan kerja menjadi faktor yang paling dirasa cukup memengaruhi kepuasan kerja. 
Promosi jabatan adalah pemindahan karyawan dari suatu posisi atau jabatan, ke posisi atau jabatan lebih tinggi dengan gaji, fasilitas, tanggung jawab, dan peluang lebih besar. Biasanya kesempatan untuk promosi pada waktu suatu organisasi mengadakan perluasan kegiatan, atau bila ada karyawan yang mencapai usia pension, atau mengundurkan diri. Namun kadang-kadang ada pula karyawan yang dipromosikan ke jabatan yang sengaja diciptakan, karena kemamuan khusus yang dimilikinya.

Untuk jam kerjanya shifting pagi 10:00-18:00 WIB dan siang 12:00-20:00 WIB. Membuat situasi kondisi yang bersahabat mengadakan tiktok kontes untuk setiap customer service supaya tidak jenuh, suasana kerja yang nyaman, selain harmonis hubungan interpersonal dengan rekan kerja, ada kondisi ruangan kerja yang nyaman.

Ada 3 faktor utama dalam kepuasan kerja, kepuasan kerja tidak hanya dapat dikelompokan dalam gaji, insentif atau penghargaan lainnya, dan promosi jabatan. Pada dasarnya pekerjaan sesuai dengan passion, bekerja dengan hati dan memiliki rekan kerja yang solid adalah kunci dari kepuasan kerja.

Grapari Telkomsel Mall Pondok Indah 3 Jakarta Selatan lokasinya sangat strategis dan mudah dijangkau, baik menggunakan transportasi pribadi atau angkutan umum lainnya.

\section{Kesimpulan}

Hubungan stres kerja dengan kinerja karyawan pada Customer service di Grapari Tekomsel Mall Pondok Indah 3 Jakarta Selatan. Berdasarkan hasil observasi wawancara dengan karyawan dan dengan pimpinan cabang GraPARI Telkomsel Mall Pondok Indah 3 maka hasil stres kerja berpengaruh negatif terhadap kinerja karyawan. Jika stres kerja meningkat maka akan mengurangi potensi kinerja karyawan dan jika sebaliknya stres kerja menurun maka akan meningkatkan potensi kinerja karyawan.

Hubungan kepusan kerja dengan kinerja karyawan pada customer service di Mall Pondok Indah 3 Jakarta Selatan. Berdasarkan observasi wawancara dengan karyawan dan dengan pimpinan cabang GraPARI Telkomsel Mall Pondok Indah 3 mengungkapkan bahwa kepuasan kerja mempunyai pengaruh yang positif terhadap kinerja karyawan. Kepuasan kerja dengan kinerja karyawan memiliki pengaruh yang positif. Hubungan tersebut mengartikan bahwa semakin puas karyawan kepada perusahaan, maka performa kerja dan hasil kerja yang ditunjukkan akan semakin baik atau sebaliknya. Dengan demikian dapat disimpulkan bahwa tinggi rendahnya kepuasan kerja karyawan akan berpengaruh terhadap kinerja. Gaji sesuai dengan jabatan kerja, pimpinan yang memperlakukan karyawan dengan baik, rekan kerja dalam bergaul tidak membedakan, perusahaan memberi fasilitas yang mendukung pekerjaan dan pekerjaan sesuai dengan harapan.

Indikator dominan yang menyebabkan stres kerja customer service Telkomsel di Mall Pondok Indah 3 yaitu menangani pelanggan hard complain. Tidak tercapainya target penjualan setiap bulan meningkat yang diberikan pada tiap masing-masing 
customer service. Pengadaan shift kerja masalah terutama kurang dapat menyesuaikan diri dengan jam kerja yang dijalankan, customer service yang meminta berganti shift. Pembagian shifting jika ada salah satu karyawan customer service yang tidak masuk maka untuk karyawan yang stand by akan long shift untuk back up yang tidak masuk.

Indikator dominan yang menyebabkan kepuasan customer service dalam memberikan pelayanan kepada pelanggan yaitu gaji diberikan tepat waktu. Insentif atau penghargaan lainnya. Rekan kerja yang bersahabat, rasa kekeluargaan yang dibangun dan rasa memiliki satu sama lain. Promosi jabatan, pada dasarnya pekerjaan sesuai dengan passion, bekerja dengan hati dan memiliki rekan kerja yang solid adalah kunci dari kepuasan kerja. 


\section{DAFTAR PUSTAKA}

Andi Prayogi, Muhammad, \& M Nursidin, M. Nursidin. (2018). Pengaruh Pelatihan dan Motivasi Kerja Terhadap Kinerja Karyawan.

Asih, Gusti Yuli, Widhiastuti, H., \& Dewi, R. (2018). Stres kerja. Semarang: Semarang University Press.

Elitear, Fadlun Maros Julian, \& Koto, Ardi Tambunan Ernawati. (2016). Penelitian Lapangan (Field Research). nd.

Erlangga, Christopher Yudha. (2017). Pengaruh Gaya Kepemimpinan, Motivasi Dan Disiplin Kerja Terhadap Kinerja Karyawan (Studi Kasus Ombudsman Republik Indonesia). Jurnal Komunikasi, 8(2).

Hastono, Hendra Indy. (2013). Hubungan kepuasan kerja dengan motivasi kerja pada karyawan Bank BTPN Madiun. UNIVERSITAS AIRLANGGA.

Lengkong, Febrio, Lengkong, Victor P. K., \& Taroreh, Rita N. (2019). Pengaruh Keterampilan, Pengalaman dan Lingkungan Kerja terhadap Kinerja Karyawan di PT. Tri Mustika Cocominaesa (Minahasa Selatan). Jurnal EMBA: Jurnal Riset Ekonomi, Manajemen, Bisnis Dan Akuntansi, 7(1).

Lucia, Roosalina Hera, Kawet, Lotje, \& Trang, Irvan. (2015). Pengaruh konflik dan stres kerja terhadap produktivitas kerja dimediasi oleh kepuasan kerja karyawan Universitas Katolik De La Salle Manado. Jurnal EMBA: Jurnal Riset Ekonomi, Manajemen, Bisnis Dan Akuntansi, 3(3).

Nilamsari, Natalina. (2014). Memahami studi dokumen dalam penelitian kualitatif. WACANA: Jurnal Ilmiah Ilmu Komunikasi, 13(2), 177-181.

Nugraha, Fajriana, \& Suherna, Suherna. (2019). Pengaruh Beban Kerja dan Komunikasi Terhadap Kepuasan Kerja Melalui Mediasi Stres Kerja Dan Hubungan Rekan Kerja (Studi Pada Karyawan Bank BJB KCU Rangkasbitung). Jurnal Riset Bisnis Dan Manajemen Tirtayasa, 3(1), 37-52.

Nurdiani, Nina. (2014). Teknik sampling snowball dalam penelitian lapangan. ComTech: Computer, Mathematics and Engineering Applications, 5(2), 1110-1118.

Nuryanti, Eka Ari. (2016). Analisis Determinan Kualitas Tidur pada Pekerja Shift Wanita di PT. Sandratex Tahun 2016. FKIK UIN Jakarta.

Qoidah, Sevyra Emelya. (2021). Analisis Atas Kinerja Karyawan Dalam Hubungannya Dengan Stres Kerja Dan Kepuasan Kerja Karyawan Customer Service Telkomsel Di Gerai Grapari Mall Pondok Indah 3 Jakarta Selatan.

Riani, Ni Luh Tesi, \& Putra, Made Surya. (2017). Pengaruh stres kerja, beban kerja dan lingkungan kerja non fisik terhadap turnover intention karyawan. Udayana University.

Samsuni, Samsuni. (2017). Manajemen sumber daya manusia. Al-Falah: Jurnal Ilmiah Keislaman Dan Kemasyarakatan, 17(1), 113-124.

Simanjuntak, Daniel Sylvester, Nadapdap, Kristanty Marina Natalia, \& Winarto, Winarto. (2017). Pengaruh Persepsi Penilaian Prestasi Kerja terhadap Kepuasan Kerja Karyawan. Jurnal Manajemen, 3(2), 6-13.

Sugiyono. (2017). MetodePenelitian Kuantitatif, Kualitatif dan R\&D. Bandung: PT Alfabet. Sugiyono. (2017). MetodePenelitian Kuantitatif, Kualitatif Dan R\&D. Bandung: PT Alfabet. 